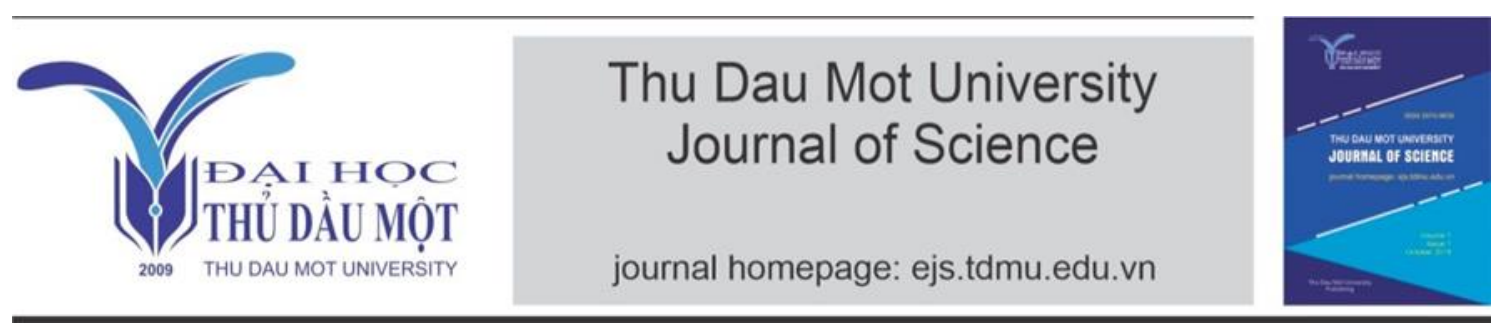

\title{
Building the intellectual contingent of Binh Duong province in the effects of industrialization and modernization
}

by Trịnh Phuơng Thảo (Thu Dau Mot University)

Article Info: $\quad$ Received 3 Mar 2021, Accepted 2 Sep 2021, Available online 15 Sep 2021

Corresponding author: thaotp@tdmu.edu.vn

https://doi.org/10.37550/tdmu.EJS/2021.03.214

\begin{abstract}
The process of industrialization, modernization and the rapid development of industrial revolution 4.0 are creating new development opportunities for the Southeast in general and Binh Duong in particular, but also setting many challenges. In order to take advantage of opportunities and overcome challenges, the role of the contingent of intellectuals in Binh Duong province is huge. Through the assessment of the current status of the development of the intellectual contingent of Binh Duong province, the article proposes basic views and major solutions to continue developing this team in the future to meet the requirements of industrialization and modernization of the country.
\end{abstract}

Keywords: intellectual contingent, Binh Duong province, industrialization and modernization

\section{Introduction}

Intellectuals are the nation's precious capital, and are the intellectual embodiment of the times. The more the society develops, the position and role of the intellectuals are more highly appreciated, especially in the context of the fourth science and technology revolution that is taking place strongly, with increasing competition for gray matter. The Communist Party of Vietnam affirmed: "In all times, knowledge has always been the foundation of social progress, intellectuals are the core force of creativity and the spread of knowledge. Today, along with the rapid development of the modern scientific and technological revolution, the intellectual team becomes a particularly important 
resource, creating the strength of each country in the development strategy". Therefore, developing the contingent of intellectuals is to improve the nation's wisdom and strength, thereby contributing significantly to the construction and development of the country according to the socialist path that the 12th National Congress of the Party affirmed "building a contingent of intellectuals who are growing stronger and of high quality, meeting the requirements of the country's development".

\section{Intellectuals and intellectuals in Binh Duong}

\subsection{The concept of intellectuals}

Nowadays, there are many different conceptions about intellectuals. On the basis of researching these concepts, we affirm that the conception of the Communist Party of Vietnam on intellectuals is a full and profound reflection, the basis and orientation for intellectual research and development current intellectual team.

Resolution No. 27-NQ/TW, 6 August 2008, 7th Conference of the Xth Central Committee on building intellectual contingents in the period of promoting industrialization and modernization of the country has confirmed: Intellectuals are intellectual workers who have a high level of education in a certain field of expertise, have the ability to think independently, create, spread and enrich knowledge, and create valuable spiritual and material products for society. Here, the concept of education includes those who are trained with a degree and who are self-taught and self-trained.

\subsection{The concept of intellectuals in Binh Duong}

On the basis of the concept of intellectuals together with the specificity of natural and social conditions in Binh Duong, we believe that: the intellectual contingent in Binh Duong is one part of the Vietnamese intellectual contingent, including creative intellectual workers, capable of independent thinking and knowledge, propagating and enriching knowledge, creating valuable products for society, living and working in Binh Duong province.

From the above concept, it is possible to understand that the intellectual team in Binh Duong is determined through the following main contents: First, the contingent of intellectuals in Binh Duong is part of the contingent of Vietnamese intellectuals; Second, the contingent of intellectuals in Binh Duong includes creative intellectual workers, with independent thinking capacity and knowledge; Third, the main function of the intellectual contingent in Binh Duong is to spread, enrich knowledge and create valuable products for social development, directly and first of all, Binh Duong; Fourth, the contingent of intellectuals in Binh Duong includes people with moral qualities and political bravery; Fifth, the contingent of intellectuals in Binh Duong includes intellectuals living and working in Binh Duong province. 


\section{The situation of building intellectuals in Binh Duong}

Binh Duong has been facing many difficulties and challenges in recent years, but with the attention of provincial leaders, the activities of Binh Duong intellectuals continue to make progress, making important contributions in the construction and development of Binh Duong.

From the practical requirements set out, on July 31, 2019, the Provincial People's Council issued Resolution No. 05/2019/NQ-HDND on policies to attract and support training and retraining to improve the quality of human resources in Binh Duong province. The policies and regulations specified in this Resolution on the one hand inherit and maintain the appropriate current policies and policies. On the other hand, based on the situation and manpower requirements of each sector or sector to consider building, adjusting or abolishing regimes and policies that are no longer suitable.

In particular, the human resources available in the society today are trained in a diverse range of occupations and qualifications while the number to be recruited is limited in terms of payroll according to regulations, especially for administrative agencies. This creates favorable conditions for agencies and units to have many choices in recruiting human resources to work. Therefore, the attraction of human resources in the coming time will not be spread out but mainly focus on a number of industries, especially health care, with the addition of specialties that need to be attracted, raising the level of support for build new policies to invite people with real qualifications and capabilities to work; maintain current attraction regimes for the remaining fields if needed.

For many years, the province has had policies and regimes for cadres, civil servants, and public employees to go to training in order to standardize the prescribed standards. Up to now, along with input recruitment standards, almost the contingent of civil servants in the province has met the prescribed standards, so it is necessary to limit the sending of cadres, civil servants, and public employees to study from the budget. Particularly, the health sector needs to promote training to ensure the structure of qualifications; the field of education and training continues to raise the standard of public employees of high school and vocational education. Therefore, the enacted policy continues to give priority to these subjects.

In addition, the policy still maintains a regime of support to encourage self-training but has adjusted and supplemented the conditions for enjoying to both ensure that civil servants and public employees are encouraged to go to school and do not affect the real show work at the office.

In order to maintain and stabilize the contingent of civil servants and public employees, the promulgated policy continues to implement monthly support regimes for cadres, civil servants and public employees with postgraduate qualifications; medical 
professional officials and employees; teachers, administrators with postgraduate qualifications in education - training, vocational education; communal cadres, civil servants and part-time workers with bachelor's and postgraduate degrees.

For the policy of attracting people to work at Thu Dau Mot University, continue to narrow the attractive audience. Accordingly, it does not attract excellent master's graduates, only attracts professors, associate professors, and doctors.

In addition, a series of policy policies can be mentioned to create conditions for intellectuals to affirm, develop, dedicate and be honored such as: policies to support the settlement of housing problems for families of young cadres, civil servants and public employees associated with the policy of using young intellectuals, policies to attract highly qualified human resources who are outsiders of Binh Duong province to work; policies to support vocational training and employment enterprises for workers in Binh Duong province, preferential regime of cadres, civil servants and public employees working in information technology and telecommunications of the province. This shows the great interest of the Province in the task of developing intellectuals in the period of promoting industrialization and modernization.

Up to now, the training and attracting human resources of the province have made positive changes, contributing to solving many problems such as: Standardizing the contingent of cadres and civil servants of the province; meeting the requirements of professional standards according to the classified category; to attract students to study disciplines at the request of the province. The Provincial People's Committee has soon issued policies and regimes to support training and training courses and regularly amended and supplemented to suit the actual situation with many preferential regimes on training costs and subsidies study, do dissertations, graduation topics, support in training and retraining in the country; to support overseas training and retraining to motivate and encourage cadres and civil servants to improve their education and attract students to work in the province after graduation; implement a number of policies to improve the youth's educational and professional qualifications, especially, building a contingent of young civil servants such as: Supplementing the training policy, attracting human resources in Binh Duong province, the policy of postgraduate training and building the contingent of young leaders and managers, a contingent of young science and technology staff, in which, has priority policies suitable to youth from policy families. The policy of supporting, fostering, and training to encourage young nurses and doctors to work at commune health stations has been implemented with practical results.

\section{The shortcomings and limitations of Binh Duong intellectuals}


However, Binh Duong intellectual team still has some limitations as follows:

The quantity and quality have not met the requirements of the development industry in the home province. The structure of the contingent of intellectuals still has unreasonable aspects in terms of profession, age, gender, and distribution in areas. The elite department, the sage is few, the leading experts are lacking, the next team is in short supply. In the province, there are not many strong scientific collective. Scientific research activities lack close attachment and have not met the diverse and rich requirements of production, business, and life.

In natural science and technology, there are still many delays and shortcomings. The number of works published in prestigious magazines in the world, and the number of inventions registered internationally is small. In social sciences and humanities, theoretical research lacks predictability and orientation, has not yet solved many problems posed by the innovation practice, has not had major creative works, many projects still have summary and copy.

The qualifications of intellectuals in many research agencies and universities have not met the development requirements of the country, especially creative capacity, practical and applied ability as well as the ability to communicate in foreign languages and use information technology.

A part of intellectuals, including those with high education levels, lack confidence, are afraid of being blamed for their views, and avoid issues that have much to do with politics. Some have decreased professional ethics, lack of sense of responsibility and self-esteem, lack of honesty and cooperation.

A part of young intellectuals are chasing immediate economic interests, lacking the will to strive for professional expertise. In part, due to the poor sense of self-cultivation and training plus the impact of the negative side of the market economy mechanism, propaganda and distortions and the manipulation of hostile forces, there have been incorrect expression of opinion, lack of passion, enthusiasm for the profession, lack of sense of civic responsibility and a distance from the Party's ideals.

The working environment in some places lacks democracy, freedom of thought, and creativity, especially for social science intellectuals and artists. The organization of cadres and management, especially the evaluation and use of intellectuals, still has many weaknesses, many points are no longer relevant. Lack of mechanisms to detect, recommend, select, foster, and recruit talents. There is a lack of policies, mechanisms and measures to create favorable conditions for intellectuals to dedicate themselves, to develop and be honored by the society with the results of their professional activities.

The current financial mechanisms and policies in science and technology, culture and 
arts activities still have many shortcomings, reducing the creative capacity of intellectuals, causing difficulties and forcing them to find ways to vice in payment procedures when performing duties.

There is no appropriate policy, strong enough to attract overseas intellectuals and foreign scientists to participate in solving the province's socio-economic development problems.

\section{Measures and policies to develop Binh Duong intellectuals}

\subsection{Raising awareness for Binh Duong people about the role of intellectuals in the current period}

First, for the masses of people. It is necessary to promote propaganda, education, training, and organization of contests and seminars. In particular, the focus is still on propaganda and education in the forms such as: organizing classes, editing educational materials. When implementing, besides popularity, it is necessary to focus on a number of objects. Typical symbols such as head of business, student.

Second, for leaders and managers. It is necessary to raise the intellectual level of Party and State committees at all levels by: improving the quality of learning, studying the Party's lines and policies on intellectuals. Leadership and managerial cadres must be flexible in each decision, approach and problem solving, especially in the wake of intellectuals' social criticisms. For those specialized in education and training, science and technology, culture and arts, it is necessary to be trained.

Third, to Binh Duong intellectuals themselves. Must be self-aware of positions, roles and responsibilities for the development of society; must not be passive, rely on, must endeavor, overcome difficulties to improve their bravery, professional qualifications, strive to rise in labor, create, and contribute to the construction and development of Binh Dương, country.

\subsection{Finalizing the policy of using Binh Duong intellectuals}

First, finalize the recruitment and appointment policy. Continue to publish recruitment information publicly. When taking the examination or selection, it is necessary to evaluate objectively. There should be flexible recruitment policies, suitable for each job position. It is necessary to promote the appointment of intellectuals through the form of examination. During the examination process, attention should be paid to the content and quality of the candidate's scheme and action program. The evaluation council must be objective and responsible.

Second, enhancing the use of young intellectuals, elderly intellectuals with talents and health. It is necessary to boldly appoint talented young intellectuals to important 
management and leadership positions; assign them to be in charge of a number of scientific topics and programs at provincial, minister level and state level under the guidance of experienced intellectuals. It is necessary to use retired intellectuals who are still healthy enough and have a lot of enthusiasm.

Third, to promote the use of intellectuals who are outside the Party. It is necessary to specify the leadership and manager positions that must be arranged by Party members and which positions are not. Should boldly assign intellectuals who are not Party members to hold professional leadership and management positions, production and business.

Fourth, make use of intellectual resources that are overseas Vietnamese. It is necessary to create a favorable and open environment, with worthy material and spiritual remuneration policies to attract more Vietnamese intellectuals abroad to Binh Duong for labor and dedication.

\subsection{Create a favorable environment and operating conditions to promote effectively the role of Binh Duong intellectuals}

First, creating a democratic and healthy social environment in the operating agencies of the intellectual contingent. In order to create a democratic environment in the creative activities of intellectuals, it is necessary to implement on the principle of democracy, the provisions of law, for the benefit of the people, for the prosperity of the province. It is necessary to build agencies and organizations of intellectual activities to unite and help each other to progress together.

Second, finalize mechanisms and policies for implementation of scientifictechnological works and financial settlement. Promoting the form of open and transparent bidding, based on the criteria for each individual and organization wishing to perform scientific and technological tasks. It is necessary to strengthen the mechanism of ordering topics and scientific and technological projects to solve urgent problems. Strengthen the inspection and supervision of financial plans for timely adjustment. It is necessary to reform the financial settlement mechanism in the direction of raising the rent limit, reducing papers. Promote financial autonomy in the process of implementing scientific and technological tasks.

Third, strengthen the cooperation between universities, centers, research institutes and enterprises. In order to overcome the limitations on human resources, material resources, promote the socialization of educational and training activities, science and technology, culture and arts, forming an educational - research - production and business complex requires a close connection between high-quality human resource training institutions and the center, research institutes; between high-quality human resource training establishments, centers, research institutes and production - business 
establishments.

Fourth, develop services, market science and technology, culture and arts. Promoting the development of science and technology services, culture and art so that the intellectuals are "hands-free", focusing on creative activities. Developing the science and technology market, culture and art not only creates an important legal basis for implementing remuneration, honoring the worthy efforts, intellect, contributions of intellectuals but also creating motivation for this team to create and contribute.

Fifth, increase the investment budget for science and technology; promote international exchange and cooperation. It is necessary to increase the investment budget for the activities of the intellectual contingent. Promote socialization, by calling on businesses to invest in building technical facilities for education and training, science and technology, culture and the arts. It is necessary to promote the expansion of international exchange and cooperation.

Sixth, to combine the consolidation and construction of a number of scientific and technological research institutions, national and international universities. It is necessary to consolidate and invest in building a number of national and international research institutions and universities in order to contribute to raising potentials, proceeding to master a number of scientific and technological achievements; on the other hand, it also creates the environment and favorable conditions for the contingent of intellectuals to effectively promote their creative capacities, attract talents, and overcome the situation of "brain drain".

\subsection{Renovation of training and fostering of Binh Duong intellectuals}

First, increasing targets, diversifying forms is associated with adjusting the structure and improving the quality of training. It is necessary to increase the size of training, especially to increase the target of post-university admissions. It is necessary to promote the forms of training: both working and learning, inter-communication, remote, second degree. Revise the training structure of intellectuals in a scientific and reasonable way. It is recommended to open some more training disciplines in the field of science and high technology that are trending to develop in the world that Binh Duong has strengths. Improve the quality of inspection and evaluation to ensure the development of quantity associated with quality, overcoming disease achievements, commercialization in education.

Second, to renew training content, programs and methods. It is necessary to review and re-evaluate all contents and programs to serve as a basis for adding new contents to ensure inter-branch, interdisciplinary and international standards. Should invite leading scientists at home and abroad, entrepreneurs to participate in consulting and criticizing the training program. Strongly renovate teaching methods, upgrade modern equipment, 
machines and technical facilities.

Third, retrain intellectuals and build a team of leading intellectuals. Periodically retrain the expertise of intellectuals, especially foreign languages and information technology. It is necessary to increase budget investment in the field of post-university training. It is recommended to recruit a number of young and promising scientists to send to countries with advanced education, science and technology in the world to train and foster to build a strong team of leading intellectuals.

Fourth, further promote the master's and doctoral programs of the Provincial Party Committee. It is necessary to increase the training targets, expand the participants, periodically evaluate to adjust in accordance with the development requirements of the province.

\subsection{Innovation of material and spiritual remuneration policies for Binh Duong intellectuals}

First, strongly reform the salary policy and the non-salary remuneration rate for the intellectuals contingent. It is necessary to strongly reform the salary policy. Salary policy must pay attention to the specificity of each type of labor and conditions in Binh Duong, based on the working position and the effectiveness of the labor, closely follow the movement and development of the society. Need to raise non-salary remuneration. There should be policies to support housing and transportation for the intellectuals team to work with peace of mind.

Second, perfecting mechanisms and policies to honor and reward intellectuals. Administrative procedures should be simplified. Public recognition should be relied on to honor intellectuals. It is necessary to raise the higher level of reward to match the contributions of intellectuals. More prizes should be built. Promote the propagating of regulations and forms of honor and commendation of intellectuals. It is necessary to promote the praise of intellectuals and scientists who have contributed to the development of provinces and countries in order to create a labor emulation and creative movement.

\section{Conclusion}

Since the innovation, the work of promoting the role of Binh Duong intellectuals has achieved some great results. However, there are still some limitations. Therefore, setting up scientific solutions to further promote the role of Binh Duong intellectuals is one of the urgent tasks today. We believe that, if the above solutions are implemented, apply not only to meet the desires of the intellectuals themselves, but also create favorable conditions for this team to promote its role effectively, making an important 
contribution in the industrialization, modernizing, developing the knowledge economy and international integration of Binh Duong.

\section{References}

MSc. Nguyen Thi Ngoc Dung (2009). Xây dưng đội ngũ trí thức trong thời kì đổi mới theo quan điểm của chủ tịch Hồ Chí Minh [Building a contingent of intellectuals in the period of innovation according to President Ho Chi Minh's point of view]. Collection of Scientific Reports, Subcommittee on Social Sciences and Humanities. Thuy Loi University. Hanoi.

Luong Huu Nam (2017). Phát triển đội ngũ trí thức ở Tây Nguyên thời kì đẩy mạnh công nghiệp hóa, hiện đại hóa [Developing intellectuals in the Central Highlands in the period of industrialization and modernization]. Doctoral thesis on scientific socialism. Ho Chi Minh City National Academy of Politics.

Bien Quoc Thang (2017). Vai trò đội ngũ trí thức thành phố Hồ Chí Minh trong giai đoạn hiện nay [The role of the contingent of intellectuals in Ho Chi Minh City in the current period]. Doctoral thesis in Philosophy. Academy of Social Sciences. Hanoi.

Thai Van Tien (2019). Bình Duoong: Chế độ, chính sách thu hút, phát triển nguồn nhân lực có hiệu lục thi hành tù̀ ngày 01/9/2019. [Binh Duong: Policies and regimes to attract and develop human resources take effect from September 1, 2019]. Department of Construction of Binh Duong province.

Doan Cong Trang (2019). Phát huy vai trò của đội ngũ trí thức trong xây dưng và phát triển Binh DivongPro [mote the role of the contingent of intellectuals in Binh Duong construction and development]. Union of Binh Duong Science and Technology Association. 